\title{
Perspectivas relacionais sobre o conhecimento e a autoridade etnográfica no Alto Rio Negro
}

Fabiane Vinente dos Santos

(UNICAMP)
Frente a um contexto de profundas transformações na região do Alto Rio Negro, Noroeste Amazônico, especialmente aquelas relacionadas ao papel do antropólogo e de suas práticas, pretendo discutir as perspectivas relacionais de antropólogos, acadêmicos indígenas e especialistas xamânicos sobre a gestão dos conhecimentos endógenos e exógenos no Alto Rio Negro. A etnografia realizada oscila entre o contexto específico de um povoado no rio Tiquié - para demonstrar como as questões abordadas se dão em um âmbito mais inclusivo - e o pano de fundo mais amplo da cidade de São Gabriel da Cachoeira, centro urbano regional e palco de boa parte das discussões públicas dos indígenas relacionadas a temas como o da educação formal.

A principal linha de pensamento defendida é a de que o papel da antropologia e do antropólogo é dimensionado de acordo com as relações estabelecidas destes diferentes sujeitos entre si, de uma perspectiva que privilegia as relações dentro do campo, tomando uma direção diferente daquela que Clifford (2008) explora em relação à chamada autoridade etnográfica, que foca em como os antropólogos construíram a legitimidade científica para "falar sobre o Outro" nas primeiras décadas do século XX. Nosso alvo aqui são as relações entre o antropólogo e os demais sujeitos da pesquisa, que são ainda mais complexas atualmente em função dos indígenas que se tornam antropólogos.

A MALOCA DE TELHAS, ANACRONISMO, MODERNIDADE E AS TRAJETÓRIAS DO CONHECIMENTO A PARTIR DE PARI-CACHOEIRA

Siripa, no alto curso do rio Tiquié, como muitas aldeias indígenas do Alto Rio Negro, abrigava até as primeiras décadas do século XX uma grande Casa Comunal, chamada em tukano de Wi'í. As Wi'i são construções cujas dimensões geralmente variam entre 20-30 metros de comprimento e até 10 metros de altura, com espaços 
diferenciados para ritos e para a vida doméstica, e habitadas por um grupo de agnatos e suas esposas, oriundas de outros grupos exogâmicos. Sua arquitetura expressa a concepção cosmológica do grupo, constituindo-se no espaço de reprodução social por excelência. A Casa de Siripa, comunidade conhecida em português como Pari-Cachoeira, pertencia ao clã tukano oriental Yeparã-Panicu, apelidados de Battitororã (sorvedores de japurá).

As Casas Comunais contavam com uma eficaz divisão de tarefas entre homens e mulheres a fim de garantir alimento, proteção e equilíbrio espiritual para todos os seus habitantes. Em sua etnografia sobre os Barasana - outro grupo tukano oriental, na Colômbia -, Christine Hugh-Jones (1979: 19) descreve a existência de cinco papéis na manutenção da Casa: o chefe (coordenação dos trabalhos comunitários), o guerreiro (chefe de guerra, responsável pela defesa contra inimigos e assaltos a grupos hostis), o servo (auxiliar do chefe), o bayá (plural bayaroá, mestres de cantos e danças) e o kumu (plural kumua, mestre de benzimentos), cada um com prerrogativas específicas. Os kumua conheciam o nome de cada criança nascida na Casa, pois eram eles quem as batizavam, de acordo com os ritos onomásticos dos Tukano. Outra figura é o yai, cujas prerrogativas na intermediação com o mundo espiritual avançam as do kumu, envolvendo o que Stephen Hugh-Jones denominou de "xamanismo vertical", que implicaria em conhecimentos esotéricos compartilhados por uma pequena elite de homens (Hugh-Jones 1996: 71).

A implantação de uma Missão Salesiana na década de 1940, com pista de pouso, hospital, igreja, escolas e internatos masculino e feminino, modificou profundamente o quadro social de Pari-Cachoeira, que passou a receber, durante as décadas seguintes, crianças e jovens de várias regiões do Tiquié que vinham em busca da escolaridade propagada pelos missionários. Com o fechamento dos internatos na década de 1980, as famílias de estudantes foram obrigadas a se mudar para o povoado durante o ano letivo a fim de acompanhar os filhos e netos durante as aulas, modificando assim a paisagem local, que se tornou cada vez mais multiétnica. Hoje, Pari-Cachoeira conta com uma população de cerca de 800 pessoas, de várias etnias - Tukano, Desana, Tuyuka, Bará, Barasana, Hupda.

Além da intervenção missionária, que introduziu novas modalidades de distribuição espacial no território do povoado, nas décadas de 1980 e 1990 Pari-Cachoeira foi alvo de uma série de intervenções por parte do projeto Calha Norte, um programa militar que acrescentou à localidade alguns elementos que convergiam com os anseios dos Tukano sobre progresso e desenvolvimento, como um mini-hospital (que nunca funcionou) e uma mini-usina hidrelétrica (que só atende ao Pelotão). Ao mesmo tempo, subtraía parte do território tradicional em uma proposta de demarcação em "ilhas" que recortava o território indígena, engendrada pelo Conselho Nacional de Segurança em Brasília com o propósito de reservar grande parte da terra para projetos de exploração mineral e madeireira. Esta proposta acabou descartada anos depois (Buchillet 1991) e substituída pela vigente, de caráter contínuo, concluída em 1997. Essa experiência, contudo, não é vista como completamente negativa por algumas lideranças Battitororã, que comentam que a atenção dada a Pari-Cachoeira por parte do governo brasileiro na época não encontrou ainda paralelos atuais. 
Em meio a tantas transformações, a presença de etnólogos no Tiquié foi uma constante, desde a passagem do etnólogo alemão Theodor Koch-Grünberg, no início do século XX. Durante meu trabalho de campo, muitas foram as ocasiões em que fui confrontada com a ideia que os indígenas faziam da antropologia. Acostumados a conviver com pesquisadores interessados em determinados aspectos de suas vidas, como os rituais das flautas Miriã (S. Hugh-Jones 1979) ou suas práticas terapêuticas, os Battitororã eventualmente demonstravam certa irritação com o que consideravam uma inconveniente insistência por parte dos antropólogos em resumi-los a esses traços.

Lutando há muitas décadas para serem vistos pelos pekasã (como chamam aos não indígenas) como aptos a usufruírem de sua tecnologia e do prestígio proporcionado por novas formas de diferenciação social trazidas pelo contato - como a escolaridade e o assalariamento -, os Tukano de Pari-Cachoeira receiam serem descritos por seus etnógrafos como "pessoas que vivem no passado". O visitante será apresentado a símbolos importantes desse esforço, como documentos, projetos e obras urbanísticas no povoado, na tentativa de mostrar o quanto eles são afeitos ao progresso e à modernidade, cuja concepção foi construída em torno do urbanismo.

Ao longo de sua história de contato, a convivência com os pekasã também proporcionou a elaboração de conhecimento a respeito de como pensam e agem os diversos tipos de pekasã com os quais se relacionaram: missionários, militares, comerciantes e antropólogos, estes últimos caracterizados por seu especial interesse na cultura indígena e, por isso, grandes conhecedores dela. Alguns dos antropólogos que circulam pelo Tiquié são apontados pelos indígenas, não sem alarme, como "gente que conhece a tradição mais do que nós mesmos".

Um fato curioso mostrou em tintas fortes a divergência entre a forma como os Battitororã se veem e a forma como representam a visão dos antropólogos sobre eles. Certa vez, durante uma reunião com várias lideranças locais na qual alguns problemas frequentes eram levantados, um dos presentes tomou a palavra e em seu discurso atribuiu tais problemas ao descontrole sobre os jovens e ao enfraquecimento dos rituais, ressaltando a necessidade de valorizar a "cultura". Logo um dos filhos do falecido kumu, que lutava internamente para ser reconhecido como sucessor do pai, sugeriu a reconstrução da Casa Comunal de Pari. Sua sugestão, apoiada por todos os presentes, também corroborava suas aspirações pessoais, pois a reconstrução da Casa Comunal, que teria a ele próprio como o mais apto para ocupar o posto de "mestre da maloca", fornecer-lhe-ia a legitimidade política para exercer o papel de kumu. A construção da Casa Comunal seria, ainda, um grande passo no sentido de reafirmar as "tradições", ou seja, os elementos tidos como mais autênticos das culturas indígenas locais - as danças, o xamanismo, a cosmologia etc., tidos como "cultura".

Uma explicação mais aprofundada do que vem a ser cultura neste contexto é necessária neste momento. Tomo aqui as reflexões de Andrello (2006), que discutiu a questão entre os indígenas tariano e tukano da localidade de lauaretê, no rio Uaupés. A cultura serviria como referência para a diferenciação não apenas entre indígenas e não indígenas, mas também dos índios entre si. 
A cultura (...) aparece como algo exclusivo dos índios, e que os distingue entre si. Já os brancos, com suas outras comidas, seriam outro tipo de gente. Não possuem cultura, pois não possuem benzimentos ou nomes cerimoniais, e suas "coisas", isto é, as mercadorias, o dinheiro, a escrita e seus conhecimentos, foram historicamente classificados como "civilização" (Andrello 2006: 277).

A reconstrução da Casa Comunal insere-se, assim, em uma discussão mais ampla, que remete à afirmação de uma especificidade enquanto unidade discreta a partir do que seriam os traços concretos da cultura: as comidas tradicionais, os cantos, a Casa Comunal, entre muitos outros elementos.

De volta à assembleia de Pari-Cachoeira, a proposta suscitou muitas conversas, todos discutindo sobre onde seria a construção, de que tamanho e como ela funcionaria. "O grande problema dessas coisas", disse um dos professores tukano em português, para que nós entendêssemos, "é que a maloca é coberta com caraná", e quase já não temos mais caraná aqui. Se ninguém mora na maloca e não faz fogo, o teto não fica bom, logo a umidade toma conta e tem que trocar a palha. Como vamos fazer isso sem caraná?".

Novo rebuliço e alguns minutos de diálogos na língua tukano ocorreram até que o líder da comunidade dirigiu-se em português aos pekasã presentes e explicou, com visível cuidado, que, devido ao problema para conseguir caraná na região, eles estavam cogitando substituir o telhado por um material industrializado - talvez telhas de barro. Fez-se um silêncio profundo no recinto.

Não posso negar que fiquei surpresa com o caráter inusitado da ideia, mas por fim ponderamos que seria uma ótima solução, pois um telhado permanente evitaria as constantes trocas de palha - embora a questão logística do transporte de tantas telhas pelo rio, além de seu custo elevado, ainda tivesse que ser solucionada. Uma das professoras que estava sentada ao meu lado exclamou, sem esconder o contentamento: "Puxa, vocês são mesmo 'antropólogos modernos'!". Como nos explicaram depois, a ideia de uma "maloca de telhas" já havia surgido outras vezes, mas eles jamais imaginariam que algum antropólogo pudesse concordar, pois, para eles, "antropólogos sempre querem ver tudo como era antigamente", o que demonstra a permanência em PariCachoeira de uma imagem essencializada do antropólogo e de seu ofício.

Em primeiro lugar, parece que a oposição entre obsoleto e moderno é uma marca dessa relação. Em linhas gerais, pode-se dizer que, pelo menos em Pari-Cachoeira, os antropólogos frequentemente são vistos pelos indígenas como amantes do anacronismo, ou seja, de um passado idealizado dominado por tradições indígenas congeladas no tempo que, insistem os Battitororã, não correspondem mais às transformações vivenciadas por eles nas últimas décadas. Essa interpretação, é bom lembrar, não é necessariamente consensual em todo o Alto Rio Negro, onde diversos projetos envolvendo profissionais como antropólogos têm contribuído para romper com dicotomias desta natureza.

Por outro lado, não deixa de ser irônico que essas interpretações guardem semelhanças com a imagem - tão combatida pela antropologia contemporânea - das culturas indígenas como congeladas no passado. Aparentemente temos uma projeção dessas representações, mas desta vez em relação ao próprio antropólogo. 
Por outro lado, essa constatação um tanto dura não deve obscurecer o fato de que antropólogos são frequentemente requisitados pelos indígenas tanto como fonte de prestígio - como quando os Battitororã reconhecem o valor político da presença de antropólogos - quanto como auxílio valioso para escrita de livros como os que têm sido editados na Coleção Narradores do Rio Negro (Andrello 2010: 281-2) - ou na escrita de projetos de valorização cultural. Minha intenção aqui é abordar alguns aspectos dessa relação complexa entre indígenas e antropólogos, buscando na forma da construção dos conhecimentos que circulam hoje no Alto Rio Negro a maneira como essa relação é desenvolvida.

Nesse campo - no sentido empregado por Bourdieu (1990) - entram em embate vários projetos tidos como "tradicionais", uma categoria nativa que envolve especialmente os conhecimentos xamânicos, tidos como "cultura" na acepção de Andrello (2006). Os principais representantes desta "tradição" são os especialistas xamânicos (kumu, yai, bayá), mas ela pode ser remanejada para outras esferas, de acordo com a conveniência dos sujeitos, incluindo os "científicos" - representados pelos antropólogos e também pelos demais pesquisadores que atuam junto aos indígenas (biólogos, linguistas, médicos, além de alguns indígenas que tiveram acesso a cursos de pós-graduação). Veremos como esses sujeitos constroem a figura do antropólogo e como este se relaciona com cada um deles. Tomei como ponto de partida a localidade de Pari-Cachoeira, mas os relatos referem-se ao Alto Rio Negro em geral, especialmente a sede urbana do município de São Gabriel da Cachoeira.

\section{CONSTITUICÃO DE SABERES}

A história de contato no Alto Rio Negro pode ser resumida em linhas gerais a partir de alguns marcos: a chegada das missões e o comércio escravagista de indígenas (1730-1760), os descimentos e aldeamentos (de 1761 até o início do século XIX), o comércio mercantil e os programas de "civilização e catequese" (1830 e 1860), o primeiro ciclo da borracha (1870-1920), o período das missões salesianas (a partir de 1914) e a era do associativismo indígena (a partir de 1990) (Cabalzar 2009: 301).

O intenso investimento da Igreja Católica na colonização da área do Alto Rio Negro, com seus 22 povos indígenas, iniciado por volta de 1914, teve como principais diretrizes a condenação das práticas xamanísticas, a dissolução das Casas Comunais (substituídas por casas nucleares) e a consolidação de um projeto nacionalintegracionista por meio da articulação de um sistema educacional pautado no dito "método preventivo" de Dom Bosco, fundador da ordem Salesiana (Camargo \& Gonçalves 2006:448). Uma rede de escolas e de internatos nas cinco sedes das Missões implantadas garantiu a escolarização em massa, ao preço alto da desestruturação da organização social das aldeias e da retirada de muitas crianças do seio familiar.

Por esse motivo, ao contrário de grande parte das áreas indígenas brasileiras, o Alto Rio Negro possui, além da rede articulada de escolas rurais com projetos de educação culturalmente diferenciada implantados pela Prefeitura Municipal, escolas criadas e autogeridas pelos indígenas, fruto de um intenso processo de articulação entre setores públicos e organizações não governamentais (ONGs) parceiras. 
É importante lembrar ainda o papel da Igreja na formação da primeira geração de indígenas com nível superior nas redes municipal e estadual de ensino. Na década de 1980, com carência de pessoal qualificado para suas escolas, a Missão Salesiana enviou vários alunos indígenas formados em seus internatos para cursos de Licenciatura em faculdades católicas existentes em outros estados brasileiros.

Além disso, a oportunidade de ingressar em um curso superior ainda hoje é franqueada aos que acenam com interesse em abraçar a vida religiosa. Em Pari-Cachoeira, um número expressivo de jovens, moças e rapazes ingressa na Missão na condição de "vocacionados". Este é um primeiro estágio para os que pretendem seguir o sacerdócio, a partir do qual podem ou não optar por continuar no processo de formação, até fazerem os votos como padres ou freiras. Vários acadêmicos indígenas passaram por esse processo e, embora a maioria não tenha chegado a tornar-se religioso, optando por retornar para casa como leigo, não foram poucos os que retornaram com um curso superior concluído e que hoje atuam como professores e diretores de escolas.

Em Pari-Cachoeira, a implantação de uma escola com internato para crianças na década de 1940 proporcionou, como vimos, o recebimento de alunos oriundos de várias partes do Tiquié que vinham estudar na Missão. Com a extinção dos internatos na década de 1980, várias dessas famílias migraram para Pari-Cachoeira a fim de acompanhar os filhos durante o período letivo. Essa adesão ao projeto de escolarização foi comum a várias áreas do Alto Rio Negro. Lasmar (2009), analisando a relação dos indígenas do rio Uaupés com a escolarização, afirma que o movimento coletivo em direção à escola, refletido no alto investimento dos pais em possibilitar aos filhos o acesso à educação formal, tem seu fundamento na busca pelas capacidades atribuídas aos brancos e seus saberes, conforme explicado nos mitos tukano e de outros povos da região. A seguir temos um resumo da narrativa conforme a versão dos Yeparã-Panicu, registrada na Coordenação Indígena de Pari-Cachoeira (CIPAC 2006):

Uma grande canoa em forma de cobra [Pirõ Yukîsi] foi criada pelos irmãos Suria-Yeki, Suriã-Parámi e sua irmã Ye'pâ-Bikió (os criadores) para ser conduzida pelo primogênito dos Tukano, Doêthiro. O que se chama hoje humanidade não existia, mas apenas um coletivo indiferenciado sob a forma de peixes. À medida que a Canoa é derrubada do céu e colocada na água para dar início à sua viagem, assume a denominação de Pã'miri-Yukîsi [Canoa da Transformação], pois será no seu ventre que as gentes irão se transformar enquanto navega por baixo d'água. Ao longo da viagem, cujo destino final será um buraco na Cachoeira de Ipanoré (no rio Uaupés) de onde as pessoas emergem, os ocupantes da Canoa da Transformação passarão por várias paradas em casas [Wi'i] ao longo do caminho. Cada casa representa uma nova capacidade ganha; eventualmente, as casas contêm aspectos negativos, como doenças e catástrofes naturais. Alguns obstáculos também aparecerão ao longo do caminho, como os ataques da serpente Seepirõ, que pode ser considerado o primeiro inimigo da criação. Ao fim da viagem, alguns dos passageiros, por diferentes motivos, não conseguem terminar as transformações necessárias para emergir em Ipanoré: o ancestral dos Pekasã [Gente da lenha de fogo, espingarda] abreviou sua própria transformação quando numa das paradas 
escolhe as armas de fogo ao invés dos adornos e após algumas peripécias ruma sozinho em direção ao sul. Os Wa'î Masã não foram considerados "prontos" e não Ihes foi permitido emergir. Continuaram na condição de peixes e, invejosos dos antigos companheiros que saíram, buscam sempre que podem atacar-lhes $e$ trocar sua "alma" pela deles.

Vários outros episódios na mesma narrativa ressaltam a impetuosidade e intrepidez dos pekasã. Se por um lado tais qualidades dão a estes um caráter por natureza antissocial e até perigoso, por outro as capacidades ganhas no processo, como a de inventar e manejar máquinas e armas e de usufruir riquezas, torna os brancos aliados desejáveis. Para Lasmar, a escola seria um canal privilegiado de compartilhamento dessas capacidades. Os indígenas do Alto Rio Negro veriam a escola como uma oportunidade de apropriação desses saberes, o que Ihes garantiria novas formas de reprodução social frente a um mundo em constante transformação.

Outro canal importante para efetuar essas mediações com o mundo dos brancos são as organizações indígenas, também fruto de um processo de busca de autonomia. Na década de 1970, missionários salesianos fomentaram as primeiras associações, visando a proporcionar aos indígenas o acesso a produtos que se tornaram então essenciais (como querosene, roupas, calçados, sabão, sal, munição, anzóis etc.) para integrá-los através do trabalho e da economia de mercado. Essas primeiras experiências associativas, que estabeleciam as chamadas "cantinas" - entrepostos de trocas de produtos rurais por produtos industrializados - proporcionaram aos indígenas a oportunidade de experimentar novas formas de intermediação, que reverberaram mais tarde na constituição de organizações próprias com bandeiras de luta política mais abrangentes, relacionadas principalmente à questão da terra.

A partir dessas primeiras experiências desencadeou-se o processo político que mais tarde deu origem à Federação das Organizações Indígenas do Rio Negro (FOIRN), fundada em 1987, organização que congrega hoje mais de 80 organizações indígenas de base do Médio e Alto Rio Negro. A demarcação das quatro principais terras pleiteadas (Médio Rio Negro I e II, Rio Apapóris e Rio Téa) teve os processos concluídos com a participação dos indígenas em 1998. No período subsequente, a FOIRN voltou-se, junto com seus parceiros, para questões ligadas à sustentabilidade dos povos indígenas de sua área de abrangência, como preservação ambiental, educação, políticas de saúde e geração de renda.

Uma das grandes conquistas da FOIRN e de seus parceiros foi a articulação de uma rede de escolas indígenas com currículos que articulam conteúdos culturalmente diferenciados - como o ensino das línguas maternas, mitologia com conhecimentos técnicos de piscicultura e agroecologia - com as matérias clássicas do currículo escolar formal (Matemática, Ciências, História etc.). Tais escolas constituíram-se em uma das estratégias dos indígenas, preocupados com a crescente evasão dos jovens das comunidades que rumavam para os centros urbanos e para as sedes das Missões em busca de concluir os estudos - pois as escolas rurais geralmente só oferecem o ensino fundamental - e não mais retornavam, além de constituírem-se em um modelo de escolarização que privilegia o 
componente da "cultura" e dos valores éticos e sociais de cada povo, apresentando-se com alternativa crítica ao modelo de escola formal implantado pelos missionários.

No que diz respeito ao ensino superior, nos últimos anos, devido às exigências da legislação educacional que estabelece a obrigatoriedade do nível superior para quem exerce o magistério, foram criados pelo poder público cursos na modalidade de Licenciatura ${ }^{2}$, tanto a convencional, direcionada às disciplinas escolares como Matemática, Ciências, Geografia etc., quanto as chamadas "Licenciaturas interculturais", voltadas para professores indígenas dos interiores dos municípios, como a Licenciatura em Políticas Indígenas e Desenvolvimento, da Universidade Federal do Amazonas.

O acúmulo de experiências na área da educação garantiu, além da escolarização de grande parte da população indígena do município de São Gabriel da Cachoeira, a inserção de professores indígenas em programas de pósgraduação na capital do Estado e em outros pontos do país. Ao lado dos cursos da área de Educação, a Antropologia tem sido um campo propenso como opção de ingresso dos estudantes indígenas. Em São Gabriel da Cachoeira, um grupo de professores indígenas pós-graduados autodenominado "Mestres Indígenas" tem promovido, desde 2010, eventos voltados para a questão educacional e a pesquisa acadêmica.

O surgimento dos indígenas antropólogos no cenário político do Alto Rio Negro também tem tido outro efeito: um interessante movimento de contestação das pesquisas e mesmo da presença de pesquisadores não indígenas. Essa questão será abordada adiante. Por enquanto é importante situar os diferentes posicionamentos frente a uma questão que tem ganhado muita importância no Alto Rio Negro: a do projeto de ensino superior voltado especificamente para os povos indígenas.

Uma das ONGs com intensa atuação na região há vários anos e que contribuiu decisivamente para o projeto de educação diferenciada desenvolvido com as organizações indígenas e com a FOIRN lançou-se em uma nova empreitada: a construção de uma universidade indígena, com conteúdos diferenciados que incorporem os chamados conhecimentos tradicionais, inclusive com a participação direta dos kumua e bayaroá.

A proposta tem sido debatida em seminários na cidade de São Gabriel da Cachoeira, para os quais são convidados a participar principalmente conhecedores tradicionais, lideranças políticas, antropólogos e outros sujeitos que atuam por meio de pesquisas na área e outros interessados no projeto. A proposta busca a captação de recursos externos e obedece a um modelo semelhante ao das escolas diferenciadas, implantadas em várias áreas indígenas pelas próprias organizações indígenas em parcerias com essa mesma ONG ao longo da primeira década de 2000. Embora nesses encontros seja destacado sempre o fato de que o projeto ainda está em construção, fica claro o desejo de estabelecer novos paradigmas, com conteúdos e metodologias diversos daqueles das universidades convencionais, definindo o que seria "uma proposta inovadora para o ensino superior indígena" (Instituto Sociambiental 2009:11), partindo da experiência das escolas indígenas já instaladas.

A ideia de uma universidade indígena conquistou outros atores no Alto Rio Negro. Um processo similar foi desencadeado pelo grupo dos Mestres Indígenas, que se constitui como um coletivo político justamente a partir do objetivo em comum da construção de uma proposta própria de universidade indígena no Alto Rio Negro. Os 
caminhos escolhidos, contudo, diferem dos da ONG: por meio de parcerias com professores da Universidade Federal do Amazonas, pleiteiam a implantação da Universidade Indígena do Rio Negro (UIRN) nos cânones acadêmicos. A proposta envolveria a extensão de cursos formais aos quais os indígenas não têm tido acesso, mas com a participação dos indígenas no planejamento, na execução e na avaliação das ações da nova instituição. Tal proposta conta com a ampla participação de professores e gestores indígenas das redes municipal e estadual de ensino nos eventos promovidos pelo grupo. Os Mestres concebem a inserção dos indígenas no sistema de ensino superior já estabelecido e com financiamento público, porém com especificidades advindas de seu diálogo com a Academia, enquanto o projeto capitaneado pela ONG busca um modelo alternativo, inspirado na experiência das escolas indígenas e visto como uma continuidade destas. Nisso talvez resida a principal diferença entre as duas iniciativas.

Assim, podemos visualizar dois projetos para a chamada universidade indígena, ambos construindo estratégias próprias de relação com os saberes do mundo dos brancos. Essa polarização reflete também na forma como cada um dimensiona a figura do antropólogo: o primeiro projeto configura-se como fruto de uma parceria entre antropólogos e demais membros de ONGs e especialistas xamânicos; o segundo estabelece-se a partir da ação de jovens acadêmicos indígenas e canais governamentais como a Universidade Federal do Amazonas. É importante lembrar que ambos os projetos são apoiados pelo movimento indígena organizado, na figura da FOIRN.

\section{REGIMES DE SABERES: ESPECIALISTAS XAMÂNICOS X ACADÊMICOS INDÍGENAS}

Cabe agora explorar mais a fundo os dois protagonistas da questão do conhecimento no âmbito indígena e de que forma cada um deles estabelece relações próprias com as práticas antropológicas: os especialistas xamânicos e os acadêmicos indígenas. O xamanismo no Alto Rio Negro reveste-se de um caráter peculiar: a origem cosmológica é continuamente revivida durante os ritos de cura e nomeação. A viagem da Cobra-Canoa é constantemente realizada em pensamento pelos kumua na ocasião dos benzimentos. Benzimento (bahsese) é como os tukano traduzem para o português os ritos de cura realizados pelo kumu ou yai, não apenas cumprindo o percurso da narrativa, mas também modificando o rumo dos eventos de acordo com sua finalidade. Determinadas paradas, conhecidas como Casas de Transformação, conforme explicado anteriormente, serão visitadas, de acordo com o objetivo do benzimento, enquanto outras serão evitadas, fornecendo um caráter interativo que em nada lembra a imagem de um contador de mitos passivo que simplesmente repete fórmulas decoradas. Por conta disso, a aprendizagem de um kumu requer grande responsabilidade, pois benzimentos malfeitos terão consequências graves para quem é tratado por ele.

Os especialistas xamânicos queixam-se do desinteresse dos mais novos a respeito das "tradições", enquanto os mais jovens alegam que não é fácil submeter-se à rígida disciplina de aprendizado para tornar-se kumu. Embora a formação do xamã no noroeste amazônico não envolva eventos de violência, como ocorre dentre alguns povos da África ou de outros lugares (Buchillet 1996), o aprendizado é rígido e o aspirante a kumu sofre uma série de 
interdições. O jejum constante não exclui somente a determinados tipos de alimentos, mas também atividade sexual, sons em alto volume, fumaça $\mathrm{O}$ kumu é alguém que raramente chama a atenção para si. Tranquilidade, recato e circunspecção caracterizam sua personalidade. Sua disciplina pessoal constitui-se em uma contínua abstinência de tudo que é excessivo aos sentidos.

O prestígio dos xamãs também sofreu duros golpes no último século. Com o fim das Casas Comunais, a influência da pressão exercida pelas frentes de contato na dissolução dos papéis rituais ganhou força. Em PariCachoeira as pessoas costumam comentar que "agora tudo é misturado", referindo-se à mistura reinante no povoado onde, além dos Battitotorã, habitam vários clãs desana e tuyuka, considerados cunhados por serem parceiros estabelecidos nas trocas de esposas, além de membros de outros clãs tukano cujos territórios tradicionais localizavam-se em outros lugares. A unidade representada pelo grupo de agnatos residente na mesma Casa Comunal, que possibilitava ao kumu conhecimento profundo sobre a vida social e espiritual da casa, não existe mais da mesma maneira. Com a substituição da maloca pelas habitações nucleares dispostas isoladamente na área das "comunidades", os saberes passaram a ser diluídos em vários níveis de profundidade, e cada homem que constitui uma família deve conhecer alguns benzimentos que lhe possibilite proteger minimamente seus filhos e sua casa. Entretanto, reconhecem que isso não é tão eficaz quanto contar com o auxílio de um kumu "de verdade".

A negligência com o saber xamânico também pode ter causas políticas. Como o conhecimento é passado de pai para filho, apenas algumas pessoas terão acesso a ele. Isto inevitavelmente fará com que esses saberes sejam inacessíveis a algumas pessoas, que jamais terão a oportunidade de dominar as narrativas e os cantos e os conhecimentos que fazem um yai, um kumu ou um bayá - pois não terão com quem "ouvir", já que as fórmulas mágicas são passadas oralmente e memorizadas pelos aprendizes (Buchillet 1996).

Há ainda outro aspecto relacionado aos riscos desse conhecimento. Como esses saberes também podem ser utilizados para agressão, e as acusações de feitiçaria por motivo de inveja são algo muito presente na vida de algumas comunidades, é arriscado para um jovem aprender alguns ritos tradicionais com alguém que não seja do mesmo grupo de agnatos, pois sempre há o risco de a relação entre mestre e aprendiz deteriorar-se e acabar em uma disputa com consequências nefastas. O sistema de transmissão de prerrogativas baseado na patrilinearidade, hierarquia e prestígio é o principal operador na gestão dos conhecimentos.

Outro exemplo de que a transmissão do conhecimento xamânico é regulada pelo parentesco pode ser encontrado em Martini (2008: 104-6), em seu relato sobre o conflito de saberes na implantação de um projeto de piscicultura em lauaretê, no rio Uaupés, entre os tariana. Enquanto os kumua afirmam que a dificuldade em reproduzir os peixes nos viveiros tem origem na não incorporação das práticas xamânicas na rotina do projeto, os técnicos indígenas insistem em tentar resolver o problema "dentro da técnica", com os conhecimentos e apetrechos que haviam adquirido nos cursos de piscicultura. A aparente desatenção em relação ao poder dos benzedores escondia, na verdade, a tentativa de busca de reconhecimento por meio do saber técnico: como o grupo de profissionais indígenas treinados não pertencia às famílias de xamãs, tendo optado pelo envolvimento com projetos como forma de obtenção de prestígio fora da esfera das hierarquias "tradicionais", ele tentava 
tornar o projeto um campo independente das capacidades mágicas. Esse episódio demonstra que as lógicas de gerenciamento dos saberes são estabelecidas de acordo com o sujeito que gerencia a relação. O saber xamânico pode, eventualmente, ser colocado de lado para dar lugar a outros estatutos de conhecimento - o que não significa que o primeiro esteja desacreditado, mas apenas que é uma fonte de prestígio tão grande que quem não tem como possuí-la pode articular alternativas.

Enquanto o minimalismo e o comedimento estão entre as principais disciplinas na formação de um especialista xamânico, a figura do acadêmico indígena não partilha do mesmo ideal de discrição. Ele é sempre colocado em evidência, chamado a assumir papéis importantes nas instâncias de intermediação das comunidades, seja como professor ou mesmo dirigindo as escolas. Destaca-se o fato de que na última década várias escolas, até então dirigidas por missionárias salesianas, foram "entregues" aos professores indígenas, que assumiram o papel de gestores, contexto no qual os cursos de pós-graduação adquiridos têm grande significado.

Embora socialmente valorizado, o saber acadêmico obtido pelos indígenas pode ser alvo de críticas pelos especialistas xamânicos. Um indígena que obtém um título acadêmico corre o risco de ser visto como alguém que está tentando burlar as regras de distribuição de prestígio a partir de uma fonte exógena ao estatuto do conhecimento dito "tradicional", como uma espécie de "alpinista social", especialmente se o indivíduo pertencer a um clã de menor prestígio.

Em um dos eventos que discutiu a Universidade Indígena, ocorrido na cidade de São Gabriel, foi possível perceber o embate velado entre os acadêmicos e os especialistas xamânicos. Um indígena do Tiquié, mestre em educação e militante da área, involuntariamente irritava um bayá enquanto discorria sobre a questão educacional. O bayá, ele próprio grande articulador da escola indígena de sua área, parecia bastante revoltado, mas, como é de praxe no Alto Rio Negro, os embates dificilmente são diretos. A elegância dos indígenas e seu apego à etiqueta de convivência impedem arroubos agressivos, mas não o debate apaixonado. Logo a divergência entre os dois ganhava ares de debate filosófico, cada um tomando a palavra para responder às provocações do outro, até que o bayá, perdendo a paciência, finalmente interpelou o acadêmico da seguinte forma:

Eu fico triste quando vejo um indígena que vai para a universidade estudar e fica colecionando mitos como se fosse um antropólogo branco. Os mitos são vivos, não são para serem colecionados. Eu uso o mito para tirar de lá um benzimento, um benefício. Não é uma coisa. Quero ver você cantar alguma coisa. Canta aí pra mim um canto do ritual de passagem [cita o nome do canto]. Canta aí. Você não sabe. Não aprendeu.

Por se ausentarem durante anos de sua casa e do berço familiar, os acadêmicos indígenas retornam detentores de um saber socialmente valorizado, mas carentes dos ensinamentos que the possibilitem aspirar ao status de conhecedor tradicional. Porque seu prestígio é oriundo de fontes externas, suas intervenções a respeito dos assuntos da "cultura" podem ser alvo de desagrado por parte dos especialistas xamânicos.

Contudo, seria ilusório pensar que tal oposição de sujeitos se estabelece apenas em termos de saberes tradicionais e saberes científicos: conflitos geracionais também estão envolvidos. Atentar para a forma como os acadêmicos indígenas dimensionam os conhecimentos adquiridos nas instituições de ensino com os conhecimentos 
tradicionais, ou como confrontam os primeiros, seria muito enriquecedor para esta discussão. Entretanto, dados os limites deste artigo, será uma tarefa a ser realizada em outra ocasião, com o cuidado que o tema demanda.

No que diz respeito à crítica sobre as práticas etnográficas explicitadas na imagem do antropólogo como "colecionador de mitos", uma das colocações mais reiteradas tanto por acadêmicos quanto por alguns especialistas xamânicos é que os mitos são registrados pelos antropólogos pekasã de forma fragmentada e descontextualizada, o que poderia esvaziar seus sentidos ou simplesmente produzir confusão quando da tentativa de tradução de conceitos tradicionais (Dutra 2010: 27).

Outra ordem de críticas está relacionada a um suposto excesso de subjetividade que estaria impregnado nas etnografias dos antropólogos, por seu apreço a conceitos e categorias nas quais as pessoas "reais" teriam dificuldade de se reconhecer. Comentando a diferença entre o seu trabalho e o de outros antropólogos que já haviam trabalhado no Alto Rio Negro, o tukano do clã Sararó Yupuri Bubera Porã, Rivelino Barreto, que obteve título de mestre em Antropologia Social pela Universidade Federal do Amazonas, coloca a questão nos seguintes termos:

O Alto Rio Negro é um palco muito bem-estudado. Mas a gente vê que muitos textos são dos gringos. É uma antropologia feita da forma deles. No meu caso, é mais concreta, prática, do que são as unidades sociais. Eles (os outros antropólogos) usam termos como "tribo", "grupos exogâmicos". Mas eu usei o termo "coletivo" no lugar de tribo. Quando se trata de grupo, se limita a um determinado local. Pode ser grupo na Colômbia, em São Domingos, em Manaus... Mas todos eles se identificam como pertencentes ao Sararó Yuúpuri Bubera Pôra. A ideia de coletivo ultrapassa as fronteiras (Barreto \& Farias 2012).

Além da ênfase no caráter formal das narrativas, os pekasã, como atesta a cosmologia, demonstram facilidade de aprendizado e tendência a apropriar-se de coisas que não são suas. $O$ envolvimento dos antropólogos com os especialistas xamânicos, por isso, apresenta sempre alguns riscos: no caso dos Yeparã-Panicu de Pari-Cachoeira, o interesse dos antropólogos nos benzimentos e na cosmologia sofre sérias restrições, que tendem a afrouxarse mediante um processo de "domesticação" paulatino. Este processo passa pelo aprendizado da língua tukano, pelo ensinamento das regras de convivência e, principalmente, pelo aguçamento da sociabilidade por meio da participação nas festas e nos trabalhos coletivos, socializando-o como a uma criança. Essa domesticação do antropólogo não indígena, como lembra McCallum no caso dos Cashinaua, nunca se realiza totalmente (McCallum 2009: 61-2), pois isso implicaria na perda das capacidades de afim potencial ${ }^{3}$.

As célebres acusações de enriquecimento dos antropólogos à custa dos indígenas também estão sempre presentes: Ao saber que meu marido estava aprendendo os princípios dos benzimentos, a esposa de um kumu preocupou-se: "Mas ele vai ficar rico benzendo lá em São Paulo!". Um artigo ácido produzido por um antropólogo indígena tuyuka (Dutra 2006) também questiona o fato de que os conhecimentos tradicionais se situarem cada vez mais dentro da lógica de mercado, transformados em recursos intelectuais e explorados da mesma forma que o são a terra, os minérios e os rios.

Essa desconfiança sempre presente, contudo, não impede que o antropólogo seja visto como fonte de reconhecimento para os velhos conhecedores. A parceria com um antropólogo é a garantia de que seu saber é 
valorizado: os filhos mais jovens do kumu passaram a se interessar pelos benzimentos ao ver que brancos de fora se interessavam por isso.

Sempre subsiste o risco da usurpação dos conhecimentos sagrados por parte do antropólogo, mas as limitações impostas por sua condição de estrangeiro, o conhecimento irrisório ou parcial da língua e sua dificuldade de concentração essencial aos especialistas xamânicos tornam pouco provável uma apropriação completa. Como nos explicou um bayá:

Algumas pessoas têm medo de os antropólogos roubarem nossos conhecimentos. Eu não tenho medo. Sabe por quê? Porque os antropólogos nunca vão entender direito as coisas. Só conseguem entender uma pequena parte, então eu nem me preocupo.

A questão do gênero tem um peso importante na mediação dessas relações. Tendo realizado meu trabalho de campo junto com meu marido, foi possível perceber as diferenças de acesso que ambos tínhamos às pessoas. Ao pedir para que um dos velhos nos ensinasse as narrativas de surgimento da humanidade, foi visível seu desconforto em relação a mim em nossa primeira sessão de trabalho. No dia seguinte, aparentemente depois de ter refletido sobre como ensinar a uma mulher as "coisas dos antigos", tidas como prerrogativas masculinas, ele nos falou que seu falecido pai, um grande kumu, teria dito que não havia necessidade de esconder nada às mulheres, pois elas um dia já foram donas desses saberes também, referindo-se ao clássico episódio mítico do roubo das flautas de Jurupari pelas mulheres (Lana 2009: 69). A explicação engendrada pelo kumu, o mesmo que busca afirmar-se como substituto do pai, aparentemente contribuiu para tranquilizá-lo e para justificar suas atitudes perante a comunidade, mas constatamos que nas ocasiões nas quais eu estava ausente as informações eram mais ricas e aprofundadas.

Um belo trabalho recente sobre benzimentos, elaborado por uma jovem antropóloga e um grupo de especialistas em uma área tukano vizinha a Pari-Cachoeira, só foi possível porque houve um acordo prévio entre os especialistas de que as informações veiculadas só fariam referência a determinados tipos de benzimento: os relacionados aos cuidados com o parto e com os recém-nascidos, temas considerados "apropriados" para uma mulher branca. Mais uma ressalva faz-se necessária aqui: algumas pesquisadoras conseguem romper as barreiras das interdições de gênero e pesquisar o xamanismo, como é o exemplo de Dominique Buchillet, cuja produção é referência nesse campo de estudo e cujas pesquisas foram realizadas no Tiquié na década de 1990.

Pode causar surpresa o fato de que os pesquisadores indígenas também compartilham algumas das limitações próprias de um estrangeiro. Mesmo um acadêmico indígena que tenha a seu lado um parente - pai, tio ou avô - que se disponha a ensinar-lhe o necessário sobre as coisas da cultura, a fim de ajudá-lo a desenvolver seu projeto de pesquisa de mestrado ou doutorado, tem que desenvolver habilidades que ampliem sua capacidade de compreensão, como informa Dutra em sua dissertação de Mestrado em Ciências Sociais sobre o xamanismo tuyuka:

Apesar de ser um genuíno tuyuka, reconheço que aqui não apresento um trabalho constituído de informações completas, que, segundo meu pai, ainda estou na primeira etapa de aprendizagem dos rituais, na qual não se pode detalhar, porque não compreenderia a linguagem “clássica" dos pajés (Dutra 2010: 27). 
Para um antropólogo estrangeiro, o acesso aos conhecimentos tradicionais tem sido cada vez mais pontuado por "trocas": ao antropólogo pekasã é mais fácil obter informações sobre cosmologia, história ou práticas xamânicas à medida que coloque suas habilidades a serviço dos povos com quem se propõe a trabalhar - como já foi dito em relação à escrita de livros e projetos. Embora isso não seja uma imposição nem uma obrigatoriedade, o entendimento de uma equivalência de valores entre os saberes tradicionais e os saberes acadêmicos enseja o estabelecimento de reciprocidade entre os detentores desses saberes.

A entrada de um pesquisador em campo no Alto Rio Negro representa um evento notório cujo impacto pode ser avaliado a partir das várias formas de "retorno" que seu trabalho pode gerar para o grupo estudado - ou seja, de quais projetos executados, tecnologias ou benefícios o grupo irá auferir resultados a partir do trabalho do pesquisador. Esta não é uma reflexão só minha, mas também de outros antropólogos que atuam na região, como Andrello, que credita seu conhecimento sobre cosmologia a esta interação em lauaretê:

O que pude conhecer sobre a cosmologia indígena do Uaupés resulta de meu envolvimento nesse tipo de discussão, e pelo fato de ter me colocado à disposição para auxiliar na redação de manuscritos sobre as histórias dos antigos. A meu ver não há outra maneira de se fazer pesquisa antropológica no Uaupés hoje, pois ali a antropologia é estigmatizada geralmente como uma atividade interessada dos brancos, e que poucas vezes trouxe algum benefício para os índios (Andrello 2006: 432).

A questão da reciprocidade, tão própria dos povos do Alto Rio Negro, conhece desta forma outras modalidades, nas quais os indígenas parecem buscar formas de socializar e repartir o prestígio aferido pelos pekasã com a elaboração das teses e dissertações elaboradas sobre eles e cujas benesses estiveram, até então, fora de seu alcance.

As tentativas de controle sobre a ação do antropólogo também existem em vários âmbitos. Determinada proposta de pesquisa pode ser negada em instâncias do movimento indígena, como a FOIRN ou as associações indígenas representativas das calhas dos rios, se for considerado que isso poderia ser prejudicial aos indígenas de alguma forma ou por não ser considerada "interessante". Para citar um exemplo, uma proposta de pesquisa antropológica que tinha como tema a religião no Içana, apreciada em reunião da diretoria da FOIRN que assisti no final da década de 1990, foi descartada com a justificativa de que "não interessava naquele momento". Poucos anos depois, o antropólogo Carlos Xavier (2008: 154) relata que durante sua pesquisa de mestrado sobre petroglifos no mesmo rio, algumas lideranças sugeriram uma proposta de pesquisa sobre a questão religiosa entre os Koripako.

De acordo com os elementos que reunimos até agora, podemos afirmar que há várias relações estabelecidas entre esses dois sujeitos chamados aqui de especialistas xamânicos e acadêmicos indígenas e uma segunda ordem de relação desses sujeitos com o antropólogo não indígena, que pode ser visualizada na Tabela 1.

Essa simplificação para efeitos didáticos não deve, contudo, impor-se sobre uma realidade bem mais complexa, na qual acadêmicos indígenas colaboram com antropólogos brancos de várias formas, seja como intérpretes-tradutores ou mesmo como informantes privilegiados, além do papel fundamental que pais, tios e avós têm para os acadêmicos indígenas, que contam com a colaboração de seus parentes da realização de suas pesquisas. 


\begin{tabular}{|c|c|c|c|}
\hline & Antropólogos & $\begin{array}{l}\text { Especialistas } \\
\text { xamânicos }\end{array}$ & Acadêmicos Indígenas \\
\hline Antropólogos & - & $\begin{array}{l}\text { Busca de tutoriamento junto } \\
\text { aos especialistas } \\
\text { Limitações de entendimento }\end{array}$ & $\begin{array}{l}\text { Colaborações mútuas } \\
\text { Apoio ao acesso a cursos de } \\
\text { pós-graduação } \\
\text { Dificuldades para reconhecer } \\
\text { o acadêmico indígena como } \\
\text { igual e não apenas como } \\
\text { fonte }\end{array}$ \\
\hline $\begin{array}{l}\text { Especialistas } \\
\text { xamânicos }\end{array}$ & $\begin{array}{l}\text { Receio de apropriação dos } \\
\text { saberes para benefício } \\
\text { econômico } \\
\text { Busca de legitimidade como } \\
\text { especialista por meio da } \\
\text { parceria com antropólogo } \\
\text { Busca por auxílio na } \\
\text { elaboração de projetos sobre } \\
\text { a questão cultural }\end{array}$ & - & $\begin{array}{l}\text { Auxílio nas pesquisas dos } \\
\text { acadêmicos indígenas } \\
\text { Relações de parentesco } \\
\text { como base (reinvenção do } \\
\text { aprendiz) }\end{array}$ \\
\hline Acadêmicos indígenas & $\begin{array}{l}\text { Tentativa de controle dos } \\
\text { antropólogos e demais } \\
\text { pesquisadores pekasã } \\
\text { Busca de reconhecimento } \\
\text { por parte dos pesquisadores } \\
\text { não indígenas e dos } \\
\text { especialistas xamânicos }\end{array}$ & $\begin{array}{l}\text { Busca de acesso aos saberes } \\
\text { tradicionais para suas } \\
\text { pesquisas }\end{array}$ & - \\
\hline
\end{tabular}

Podemos então ler uma nova inversão das relações entre kumu e aprendiz, em uma nova roupagem: se antes aprender o ofício de kumu, bayá ou yai só seria completamente seguro se fosse com um parente direto, hoje um acadêmico indígena que deseja realizar sua pesquisa deverá contar com o respaldo da relação de parentesco com um especialista, o que lhe garantirá a boa vontade para ter acesso a informações relacionadas aos saberes tradicionais que, de outra forma, Ihes seriam interditados. Nessa relação, a legitimidade é fornecida pelo conhecedor, cujos títulos e reconhecimento social serão revertidos em benefício do trabalho de pesquisa de seu parente acadêmico.

A Tabela 1 também deixa de fora as relações de competição ou cooperação entre os pares antropólogos/ antropólogos, especialistas xamânicos/especialistas xamânicos, e entre os acadêmicos entre si, que embora sejam profícuas e com potencial de análise, não entraram nesta discussão, carecendo de uma abordagem mais aprofundada. Alguns aspectos interessantes destas relações foram explorados por Flora Dias-Cabalzar (2010) em uma tese recente. 


\section{CONCLUSÃO}

Ao longo de sua história de contato, os povos do Alto Rio Negro experimentaram várias formas de relação com o mundo dos brancos, dentre as quais a pesquisa acadêmica. A autodeterminação preconizada pelo movimento indígena reflete-se também na forma como essas pessoas lidam atualmente com a pesquisa antropológica.

Embora a legislação brasileira de ética em pesquisa estabeleça a necessidade de consentimento esclarecido por parte de quem sofreu algum impacto com ela, não há um controle rígido sobre a entrada de pesquisadores em áreas indígenas, sejam eles antropólogos ou pesquisadores de outras áreas ${ }^{4}$, como biólogos. Por conta disso, os Mestres Indígenas constituíram uma instância de regulação, no formato de Conselho Deliberativo de Ética em Pesquisa Indígena, instituído durante o I Simpósio Diálogos Interculturais na Fronteira Amazônica, ocorrido na Maloca da FOIRN em setembro de 2011, que teria como papel a análise das propostas de pesquisa com mais rigor do que vem ocorrendo, com a possibilidade de vetá-las - como preconiza o "deliberativo" do título da instância.

A criação de um conselho desse tipo demonstra a tentativa de articulação de um projeto indígena para lidar com a realidade das pesquisas e com o assédio dos pesquisadores - embora seja perceptível que a proposta carece de mais respaldo por parte das lideranças e das comunidades a quem querem representar, já que nega a cada localidade seus próprios mecanismos de negociação com as pesquisas. É notório, contudo, que a criação desse Conselho expressa a insatisfação de boa parte dos indígenas com relação ao que consideram uma nova forma de abuso dos brancos: a apropriação de seus "conhecimentos tradicionais" por meio de uma miríade de projetos de pesquisa estabelecidos fora dos circuitos de reciprocidade locais. Nesse sentido, os questionamentos dos indígenas sobre a competência dos antropólogos para desenvolver pesquisas "interessantes" aos próprios indígenas, e sobre a necessidade de formar seus próprios antropólogos, revestem-se não apenas de um caráter político, mas também tentam enquadrar o conhecimento antropológico nas redes de compartilhamento de bens.

De um conhecimento "egoísta", cujos benefícios materiais e subjetivos (como o prestígio acadêmico) sempre ficaram fora de seu alcance, os indígenas tentam construir novas bases de relação que socializem a antropologia, enquadrando-a por intermédio dos acadêmicos indígenas nas redes de parentesco e por meio do recrutamento de antropólogos não indígenas aos circuitos de trocas existentes.

Fabiane Vinente dos Santos é Doutoranda no Programa de Pós-Graduação em Antropologia Social da Universidade Estadual de Campinas e pesquisadora do Centro de Pesquisa em Etnologia Indígena da Unicamp e do Instituto Leônidas e Maria Deane, Fundação Oswaldo Cruz. 


\section{NOTAS}

1 Denominação da Bactris Cuspidata, palmeira da família das Arecáceas utilizada para a forragem do telhado da Casa Comunal tradicional. Em função de seu uso nas casas nucleares, a palmeira tem se tornado cada vez mais rara no Tiquié, obrigando quem queira obtê-la a empreender longas viagens a trechos mais inóspitos da região. Isto torna sua obtenção extremamente dispendiosa em função do combustível necessário para as embarcações e dinheiro para ressarcimento dos auxiliares.

2 A modalidade de graduação denominada "Licenciatura" caracteriza-se principalmente por ser uma formação voltada para o magistério, ao contrário do "Bacharelado", que teria um perfil mais voltado para a pesquisa ou para a aplicação dos conhecimentos, dependendo da área do conhecimento. A primeira licenciatura em São Gabriel da Cachoeira foi realizada em 1992, sob a forma de um curso em módulos.

3 Andrello (2004: 409), a partir da célebre distinção entre afim potencial e afim efetivo de Eduardo Viveiros de Castro, discute como no Alto Rio Negro o "branco" ocupa esse papel de afim potencial: "Neste sentido o branco ocuparia, tanto quanto o inimigo, a posição de um afim potencial, que aqui é fonte não de cônjuges, mas de outros itens simbólicos e materiais".

4 Um grande debate nacional tem tomado a atenção dos antropólogos. Eles julgam que a atual legislação de ética em pesquisa (Resolução n. 196 do Conselho Nacional de Saúde), como referência principal, foi criada com base nos critérios das pesquisas Biomédicas, e é problemática quando aplicada à pesquisa em Ciências Humanas. Para um panorama do debate na Associação Brasileira de Antropologia, ver Victora et al. (2004). Sobre a dificuldade de enquadramento das pesquisas das áreas de humanas nos critérios da Resolução 196, ver MacRae \& Vidal (2006). 


\section{REFERÊNCIAS BIBLIOGRÁFICAS}

ANDRELLO, Geraldo. 2006. Cidade do Índio. São Paulo: Editora UNESP: ISA; Rio de Janeiro: NUTI.

2010. "Falas, objetos e corpos. Autores Indígenas no Alto Rio Negro". Revista Brasileira de Ciências Sociais 25 (73): 5-26

BARRETO, Rivelino \& FARIAS, Elaíze. 2012. “Palavra de Mestre: Entrevista de Rivelino Barreto”. A Crítica. Disponível em: http://acritica.uol.com.br/amazonia/Manaus-Amazonas-Amazonia-antropologia-incentiva-abandonarconhecimento-tradicionais_0_686931312.html

BOURDIEU, Pierre. 1990. Coisas Ditas. São Paulo: Brasiliense.

BUCHILLET, Dominique. 1991. "Pari-Cachoeira, o laboratório Tukano do Calha Norte". In B. Ricardo (org.). Povos Indígenas no Brasil 1987/88/89/90. São Paulo: CEDI.

.1996. "Nobody is there to hear: Desana Therapeutics incantations". In J. Langdon \& G. Baer (eds.). Portals of Power: shamanism in South America. Albuquerque: University of New Mexico Press.

CABALZAR, Aloisio. 2009. Filhos da Cobra de Pedra: Organização social e trajetórias tuyuka no rio Tiquié (Noroeste Amazônico). São Paulo: NUTI; ISA.

CAMARGO, Dulce Maria Pompeo \& GONÇALVES, Judite Albuquerque. 2006. “O eu e o Outro no ensino médio indígena: Alto Rio Negro (AM)". Educação e Sociedade 27 (95): 445-469.

CLIFFORD, James. 2008. "A autoridade etnográfica". In A experiência etnográfica. Antropologia e literatura no século XX. Rio de Janeiro: EdUFRJ.

COORDENAÇÃO INDÍGENA DE PARI-CACHOEIRA (CIPAC). 2006. Kumuá Naâ Uúkuse-Basesé. Origem do Mundo e da Humanidade. A sabedoria dos ancestrais Tukano do Rio Tiquié. Recife: SSL; CIPAC.

DIAS-CABALZAR, Flora. 2010. Até Manaus, até Bogotá. Os Tuyuka vestem seus nomes como ornamentos: geração e transformação de conhecimentos a partir do alto rio Tiquié (Noroeste Amazônico). Tese de Doutorado. São Paulo: Programa de Pós-Graduação em Antropologia Social, Universidade de São Paulo.

DUTRA, Israel Fontes. 2006. “Risco e importância da pesquisa científica no contexto da Amazônia e dos Povos Indígenas". Revista PUCVIVA 27.

2010. Xamanismo Uhtapinõpona. Princípios rituais de pajelança e do ser pajé tuyuka. Dissertação de Mestrado. São Paulo: Programa de Pós-Graduação em Ciências Sociais, Pontifícia Universidade Católica de São Paulo.

HUGH-JONES, Christine. 1979. From the Milk River: spatial and temporal processes in Northwest Amazonia. Cambridge: Cambridge University Press.

HUGH-JONES, Stephen. 1979. The palm and the pleiades: initiation and cosmology in Northwest Amazonian. Cambridge: Cambridge University Press.

. 1996. "Shamans, prophets, priests and pastors". In N. Thomas, Nicholas \& C. Humphrey (orgs.). Shamanism, History and The State. Michigan: The University of Michigan Press. 
INSTITUTO SOCIOAMBIENTAL. 2009. Projeto de formação superior indígena, interdisciplinar e multicultural no rio Negro. São Gabriel da Cachoeira: Federação das Organizações Indígenas do Rio Negro; Instituto Socioambiental.

LANA, Feliciano. 2009. A origem da noite e Como as mulheres roubaram as flautas sagradas. Manaus: Editora da Universidade Federal do Amazonas.

LASMAR, Cristiane. 2009. “Conhecer para transformar: os índios do rio Uaupés (Alto Rio Negro) e a educação escolar". Tellus 9 (16): 11-33.

MACRAE, Edward \& VIDAL, Sergio Souza. 2006. "A Resolução 196/96 e a imposição do modelo biomédico na pesquisa social. Dilemas éticos e metodológicos do antropólogo pesquisando o uso de substâncias psicoativas". Revista de Antropologia 49 (2): 645-666

MARTINI, André Luiz. 2008. Filhos do Homem: A introdução da Piscicultura entre Populações indígenas no povoado de lauaretê, rio Uaupés. Dissertação de Mestrado. Campinas: Programa de Pós-Graduação em Antropologia Social, Universidade Estadual de Campinas.

MCCALLUM, Cecilia. 2009. "Becoming a real woman: alterity and the embodiment of Cashinaua gendered identity". Tipití: Journal of the Society for the Anthropology of Lowland South America 7 (1): 43-66.

VICTORA, C. et al (orgs.). 2004. Antropologia e ética: o debate atual no Brasil. Niterói: EDUFF.

XAVIER, Carlos Cesar Leal. 2008. A cidade grande de Ñaperikoli e os petroglifos do Içana - uma etnografia de signos baniwa. Dissertação de Mestrado. Rio de Janeiro: Programa de Pós-Graduação em Antropologia Social, Museu Nacional, Universidade Federal do Rio de Janeiro. 


\section{Perspectivas relacionais sobre o conhecimento e a autoridade etnográfica no Alto Rio Negro}

\section{RESUMO}

O artigo aborda as perspectivas relacionais de antropólogos, acadêmicos indígenas e especialistas xamânicos sobre a gestão dos conhecimentos endógenos e exógenos no Alto Rio Negro. As relações de colaboração e/ ou antagonismo estabelecidas, a figura do etnógrafo e o papel da antropologia como instância de legitimação/ deslegitimação dos sujeitos envolvidos neste processo são os objetos da discussão.

PALAVRAS-CHAVE: Alto Rio Negro; autoridade etnográfica; conhecimento

\section{Relational Perspectives on knowledge and ethnographic authority in the Upper Rio Negro}

\section{ABSTRACT}

The article approaches the relational perspectives of anthropologists, indigenous academics, and shamanic specialists on the management of endogenous and exogenous knowledge in the Upper Rio Negro region. The established relationships of collaboration and/or antagonism, the role and figure of the ethnographer, and the role of anthropology as a means of legitimation/delegitimation of the subjects involved in this process are the topics of discussion.

KEY WORDS: Upper Rio Negro; ethnographic authority; knowledge 